\title{
The Effectiveness of Cooperative Integrated Reading and Composition (CIRC) Technique on Students' Reading Comprehension: A Study at the Grade Seven of MTsN Koto Baru Junior High School, West Sumatera, Indonesia
}

\author{
Dodi Widia Nanda*
}

\author{
University of Dharmas Indonesia (UNDHARI)
}

\begin{abstract}
Indonesian junior high school students have been asked by the Indonesian Ministry of Education and Culture to understand various English texts effectively. However, reading comprehension has been considered a major issue in the Indonesian EFL context including in the junior high schools. Therefore, in an attempt to comply with the required criteria above, this paper proposed a possible solution to cope with Indonesian students' reading comprehension issue. In this sense, CIRC was proposed as a treatment to enhance Indonesian junior high school students' reading comprehension. Specifically, this research attempted to measure the effectiveness of CIRC technique on students' reading comprehension at grade seven of a junior school located in West Sumatera, Indonesia namely the MTsN Koto Baru Junior High School. Accordingly, the study employed quantitative methodology, specifically the quasi-experimental design which compared students' pre-test and post-test to measure the effectiveness of CIRC toward students' reading comprehension. The different result between the pre-test and post-test was tested using the paired sample t-test, which was found that students' scores on pre-test (before treatment) was lower than post-test (after treatment). Thus, it could be inferred that CIRC was effective to increase students' reading comprehension.
\end{abstract}

Keywords: Reading comprehension; CIRC technique; junior high school; EFL context

Introduction, Background, Nature, and Significance of the Research

Reading comprehension has been considered a predominant problem for Indonesian junior high school students. It is supported by a study conducted by Syatriana (2013), stating that Indonesian junior high school students often have difficulties in comprehending various English texts well. The first leading factor of their poor reading comprehension is the lack of motivation, in which they are not interested in conducting reading activities due to their learning habits (Syatriana, 2013). In other words, they have less motivation to analyse reading passages since they rarely deal with such activities in their daily routines. Moreover, they merely intend to read English texts if teachers give them assignments (Syatriana, 2013). Consequently, it may result in their poor abilities in comprehending English texts.

Secondly, poor background knowledge is considered another leading factor in students' reading comprehension issue. It is found that they have difficulties in understanding English texts because they might not have sufficient background knowledge to analyse the given English texts (Syatriana, 2013). The related condition may happen because they rarely read various reading passages previously (Syatriana, 2013). In contrast, students are required to draw inferences that lean to their background knowledge to scrutinise English texts effectively (Neuman et al., 2014). 
Thirdly, the lack of vocabulary is considered the third factor that affects students' reading comprehension issue in the context of Indonesian junior high school. It is supported by Floris and Divina (2009), postulating that limited vocabulary is identified as the hindrance of reading comprehension skills among Indonesian learners. Moreover, the Indonesian Government suggests that learners should master between 2500 to 3000 English words to understand English texts well; however, Indonesian junior high school students have merely mastered around 1000 words (Floris \& Divina, 2009). As a consequence, the aforementioned condition might lead to reading comprehension issues among Indonesian junior high school students. Consequently, this condition may result in two adverse ramifications which are explained below:

Decreasing students' learning achievement might be considered the first adverse consequence of poor reading comprehension issue in the Indonesian junior high school context. It occurs because students have low selfesteem after having difficulties in analysing English texts (Guthrie \& Davis, 2003). Moreover, struggling readers tend to be marked as less valued members in the classroom. It is supported by a study conducted by Guthrie and Davis (2003), stating that struggling readers tend to feel socially marginalised when they unsuccessfully engaged with English passages. Additionally, they are likely to avoid studying and procrastinate the assigned works (Guthrie \& Davis, 2003). Consequently, it could affect their concentration on learning and gradually reduce their learning achievement. Secondly, hindering students' problem-solving skill might be categorised as another negative impact of poor reading comprehension. It is likely to occur since reading is an essential part of solving problems (Ozdemir, 2009). In other words, students are required to analyse texts firstly before addressing questions and problems which are given in the texts (Mehl, 1985). This view is supported by Hite (2009), revealing that her students having difficulties in reaching solutions to solve case problems which are provided in course questions due to their lack of reading comprehension skills.

In contrast to the condition above, the newest Indonesian curriculum, the Curriculum 2013 under the Regulation of Ministry of Education and Culture (2013) mandates the Indonesian learners in the junior high school level to comprehend various English texts effectively. Therefore, in an attempt to comply with the assigned instruction above, the paper offers a possible technique to deal with poor reading comprehension issue among Indonesian junior high school students, which is the CIRC. The technique might be advantageous to address students' poor reading comprehension issue since it is believed as one of the possible techniques that can be applied to deal with two adverse effects of poor reading comprehension issues which are delineated previously, decreasing learners' achievement and hindering problem-solving skills (this instance will be elaborated in detail in the literature review part).

Ultimately, the result of the paper is aimed at providing benefits for EFL learners, teachers, researchers and the Indonesian educational stakeholders. For example, the research outcome can be utilised as a valuable selfreflection by EFL learners to cope with reading comprehension issues. Additionally, EFL teachers and researchers could lean on the proposed solutions which are provided in the paper to scrutinise students' reading comprehension issue in English. Lastly, it is hoped that the investigation might be advantageous for Indonesian educational stakeholders in order to provide certain training to EFL teachers regarding reading strategies that can be used by them to tackle reading comprehension issues in the Indonesian junior high school context.

\section{Literature Review}

\section{Theoretical Framework}

\section{Reading Comprehension}

Reading comprehension is considered one of the reading skills that must be effectively mastered by learners. It happens because skilled readers might attain considerable inputs from what they have read compared to unskilled readers (Snow, 2002). In other words, skilful readers may have easiness to scrutinise some valuable 
information, data and knowledge which are provided in some sources like reading passages, texts, books, journals and others. Consequently, the condition above may enhance their cognitive skills in their daily lives.

Additionally, Snow (2002) reveals that reading comprehension is defined as the activity of fostering and extracting meaning simultaneously by using interaction and engagement with written language. In other words, reading comprehension is considered a comprehensive process that students have to read to attain a comprehensive understanding. Specifically, Klingner (2007) argues that reading comprehension is considered the process of establishing meaning by coordinating some complex processes such as fluency and word reading. In other words, students are required to activate their prior knowledge and construct meaning effectively in order to grasp the valuable information which is provided in the given texts. More importantly, students are asked as well to familiarise with a wide range of vocabularies in order to analyse and comprehend these given texts effectively (Klingner, 2007).

\section{Indicators of Reading Comprehension}

Generally, Brown (2004) proposes seven indicators in reading comprehension which are needed by students to understand the given English texts effectively. These seven indicators are explained below:

\section{Main idea}

There are two aspects that are required in the first indicator; firstly, learners should be able to analyse the topic and main idea which are provided in the texts effectively. Secondly, students are needed to identify the aim of the provided texts accurately.

\section{Expression/idiom}

Students must be able to identify phrases, idioms and expression effectively.

\section{Grammatical features}

Students must be able to analyse generic and rhetorical structures which are given in the text accurately.

4. Detail

Learners are required to identify the wide range of correct information which is stated in the assigned texts.

\section{Excluding fact}

Students must be able to identify and predict certain information that is not stated in the texts.

\section{Supporting detail}

In this indicator, students are hoped to analyse supporting details which are given in the text accurately.

7. Vocabulary in the context

There are two predominant aspects which are required in this indicator. The first aspect is that learners are hoped to identify vocabularies based on the context accurately. The second aspect is that students must be able to analyse new vocabularies related to the information which is given in the text. 


\section{The Cooperative Integrated Reading and Composition (CIRC) Technique}

Based on the discussion which is delineated in the first part of the essay, decreasing student' learning achievement and hampering their problem-solving skills are considered the possible negative consequences of poor reading comprehension issues. Hence, CIRC might be useful to cope with the related adverse consequences. The first reason is that CIRC can be considered a possible technique that can be implemented to enhance learners' problem-solving abilities (Slavin, 2005). It occurs because students will be given significant opportunities to share their experiences with their colleagues in collaborative forms, leading them to understand incoming information and knowledge that they do not know previously (Slavin, 2005). Moreover, in the designed activities of CIRC, learners are asked to collaborate with their teammates on a series of cognitive activities like responding to stories, reading to one another, making a prediction, and informing the meaning of certain English vocabularies (Slavin, 2005). Consequently, it may automatically foster students' problemsolving skills since they have enough opportunities to explore and share their insights with their teammates.

The second reason is that CIRC might be advantageous as well to increase learners' motivation in studying. Working in groups may offer them such convincing feeling that they could finish assigned activities effectively. This positive feeling may be difficult to achieve by students if they work individually (Slavin, 1996). Moreover, a study conducted by Varisoglu (2016), showing that CIRC is effective to enhance students' motivation in conducting reading comprehension activities. The result shows that learners are being motivated in following assigned group activities, which increases their reading comprehension skills (Varisoglu, 2016). Hence, based on the condition above, it could be assumed that the practice of CIRC is effective to motivate students in engaging with reading comprehension activities. However, a study conducted by Liu and Wang (2015), showing a different result. The outcome delineates that students perform better when they work individually than collaborating in group activities. It happens because studying independently leads them to read quietly without being distracted by other students.

In order to refute the argument above, the weaknesses of the implementation of CIRC above can be minimised in the junior high school context because the students might be mature enough to manage the possible distraction when it happens in the classroom, leading them to focus on accomplishing assigned reading activities. Consequently, it may give way to the consistency of their learning achievement concerning reading comprehension. The view above is supported by Slavin (1996), postulating that the CIRC technique has offered a positive impact on students' reading comprehension if it is applied in the junior high school context. Moreover, the positive achievement has been counted about twenty-three out of thirty studies, and it is equal to seventy-seven percent (Slavin, 1996). Hence, it can be deemed that there might be a higher possibility of the successful practice of CIRC if it is employed in the Indonesian junior high school context as well.

\section{Hypothesis of the Research}

The hypothesis of the research is a tentative statement, in which it is believed that CIRC is effective to enhance students' reading comprehension. Specifically, in this research, the writer hypothesises that CIRC technique might be helpful to increase students' reading comprehension at the grade seven of MTsN Koto Baru Junior High School, West Sumatera, Indonesia in the academic year of 2017/2018. Additionally, Notoatmodjo (2010) proposes the pattern of the hypothesis as below:

$\mathrm{H}_{0}$ : there is no significant effect of CIRC technique toward students' reading comprehension.

$\mathrm{H}_{1}$ : there is a significant effect of CIRC technique toward students' reading comprehension. 
The result of test:

- If sig. (2-tailed) $>0.05$, it means $\mathrm{H}_{0}$ is accepted.

- If sig. (2-tailed) $<0.05$, it means $\mathrm{H}_{0}$ is rejected.

\section{Research Methodology}

\section{Research Design}

In this paper, the researcher applied a quantitative methodology, specifically the quasi-experimental design. Ali (2014) defines the quasi-experimental design as a type of research that focuses on people as the subject. Specifically, the research selected one sample group pre-test-post-test. It means the writer merely observed a class, in which the result of pre-test and post-test was compared in order to measure the effectiveness of CIRC toward students' reading comprehension. To be specific, the experimental class was observed before the treatment, called pre-test $\left(0_{1}\right)$. Whereas, the observation after the given experiment is called post-test $\left(0_{2}\right)$, and the treatment is mentioned as $\mathrm{X}$ (Notoatmodjo, 2010).

\section{Population and Sample}

Notoatmodjo (2010) defines a population as a member of people, things and even animal that live together in a particular place which is planned as the research target. Hence, the research population was all of the students in grade seven of MTsN Koto Baru Junior High School that were registered in the academic year of 2017/2018; it was about 283 students. On the other hand, the sample could be classified as part of the population (Notoatmodjo, 2010). In this research, the writer applied the cluster-sampling technique, in which cluster sampling is defined as the process of choosing a sample from the intact group (Ali, 2014). Therefore, the researcher merely selected one class as the sample, class A of the seventh-grade students of MTsN Koto Baru Junior High School; it was 43 students. The reason of selecting class A because the class was taught with all kinds of English texts which have been suggested by the Indonesian curriculum such as descriptive, narrative, recount, and other texts (Ministry of Education and Culture, 2013). Moreover, class A was chosen as well because it could fulfil the balanced gender representation of participants, in which it consisted of 22 female and 21 male students. Therefore, class A was selected as the sample instead of other classes in grade seven of MTsN Koto Baru Junior High School, West Sumatera, Indonesia.

\section{Technique of the Data Collection}

The writer collected the data by giving multiple choice tests to students, comprising the pre-test and post-test. The pre-test was given before the researcher taught students with the CIRC as the treatment, whereas the posttest was implemented after the writer taught students the reading materials with the CIRC. In order to validate the instruments, the given questions in the multiple-choice tests were consulted with one of the lecturers in the English Department of University of Dharmas Indonesia. Whereas, in order to present the reliability of the test, the questions were carefully created based on the materials and syllabus of grade seven in the Indonesian junior high school context.

\section{Technique of the Data Analysis}

After the data were collected, they were further analysed by using the statistical software of computer program namely the SPSS 16 for calculating T-test with the standard error 5\%, which was formulated as follow (Notoatmodjo, 2010): 


$$
t=\frac{\bar{X}_{1}-\bar{X}_{2}}{\sqrt{\left(S_{1} / n_{1}\right)+\left(S_{2} / n_{2}\right)-2 r\left(s_{1} / \sqrt{n_{1}}\right)+\left(s_{2} / \sqrt{n_{2}}\right)}}
$$

Where:

$S_{1} \quad=$ The first variant of the variable

$\mathrm{S}_{2} \quad=$ The second variant of the variable

$\mathrm{s}_{1} \quad=$ The first standard deviation of first variant

$\mathrm{s}_{2} \quad=$ The second standard deviation of second variant

$\mathrm{X}_{1} \quad=$ The average of first variant

$\mathrm{X}_{2} \quad=$ The average of second variant

Conclusion:

$\mathrm{H}_{0}$ is rejected if the sig. (2-tailed) $<0.05$ (Notoatmodjo, 2010).

\section{Findings and Discussions}

\section{Findings}

\section{Data Presentation}

\section{Pre-test Data}

The pre-test was conducted on 30 April 2018, and it was done to measure students' reading comprehension abilities before the treatment. The average score of the pre-test was counted for about 58.9, whereas the highest and lowest score was around 80 and 44, respectively. Specifically, the result of the pre-test is attached in (Appendix I), and the descriptive statistic of the pre-test is drawn below:

Table 1: The descriptive statistics of the pre-test

\begin{tabular}{|l|r|r|r|l|}
\hline & $\mathrm{N}$ & Minimum & Maximum & Mean \\
\hline $\begin{array}{l}\text { Pre Test } \\
\text { Valid N } \\
\text { (listwise) }\end{array}$ & 43 & 44.00 & 80.00 & 58.8837 \\
\hline
\end{tabular}

\section{Post-test Data}

The post-test was conducted on 23 May 2018, and it was given after students were taught using the CIRC as the treatment. To be specific, in this given treatment, students were assigned to discuss the given English texts including descriptive, narrative, recount and others in the group work for eight meetings, in which each meeting consisted of two hours. Moreover, as the notion of CIRC as the given treatment in this research, one more capable student in each group was appointed as group leaders to assist other students who were detected as lowproficient learners in comprehending English texts. It helped those low-proficient students to improve their reading comprehension abilities because they could share their insights toward the given texts with their colleagues. Consequently, it was found that there was remarkable different between students' scores in the pretest and post-test. It could be seen in the average score of the post-test, which was stood at 83.2. Meanwhile, the highest and lowest score was counted for about 96 and 60, respectively. The result of post-test is attached in (Appendix II), and the descriptive statistic of the post-test is delineated below: 
Table 2: The descriptive statistics of the post-test

\begin{tabular}{|l|r|r|r|l|}
\hline & \multicolumn{1}{|c|}{ N } & Minimum & Maximum & Mean \\
\hline Post test & 43 & 60.00 & 96.00 & 83.1628 \\
Valid N \\
(listwise )
\end{tabular}

\section{Data Analysis}

\section{Pre-test and Post-test Analysis}

Table 3: Frequency distribution on pre-test

\begin{tabular}{|l|c|c|c|c|}
\hline NO & Score & Absolute Frequency & Relative Frequency & Criteria \\
\hline 1 & $44-60$ & 25 Students & $58 \%$ & Fair \\
\hline 2 & $64-80$ & 18 Students & $42 \%$ & Good \\
\hline
\end{tabular}

Table 4: Frequency distribution on post-test

\begin{tabular}{|c|c|c|c|c|}
\hline NO & Score & Absolute Frequency & Relative Frequency & Criteria \\
\hline 1 & 60 & 2 Students & $5 \%$ & Fair \\
\hline 2 & $68-80$ & 17 Students & $40 \%$ & Good \\
\hline 3 & $84-96$ & 24 Students & $55 \%$ & Very Good \\
\hline
\end{tabular}

Based on the two tables of frequency distribution on pre-test and post-test above, it can be inferred that there was a significant difference made by students before the treatment (pre-test) and after the treatment (post-test). On the one hand, the table of frequency distribution on pre-test illustrated that the students' average scores in the pre-test were still categorised in the low level. It can be seen from the presented data; there were merely two criteria which were found in the pre-test, fair and good. Specifically, there were 25 students, $58 \%$, got the average scores between 44-60, and it could be included in the fair criteria. Meanwhile, the rest of 18 students, 42 $\%$, obtained the average score between 64-80, and they were categorised in the good criteria. Hence, based on the explained data, it can be concluded that students' abilities and scores concerning reading comprehension before the given treatment were still low.

On the other hand, in the table of frequency distribution on post-test, students' scores on reading comprehension after the given treatment experienced a remarkable rise. It can be seen from the illustrated data; there were merely two students who still attained the scores of fair criteria, 60. Whereas it was about $40 \%, 17$ students, 
reached the average scores between 68-80, and they were categorised in the good criteria. Additionally, the rest of the 24 students had successfully achieved the highest criteria, the very good criteria. Interestingly, the average scores between 84-96 were counted until $55 \%$ of the total of the students. Thus, based on the data above, it can be inferred that there had been considerable increase made by students concerning their scores in reading comprehension after they are taught with the CIRC, as the given treatment.

\section{Hypothesis Test}

As explained in the literature review of this research, the hypothesis of the research was "the CIRC is believed as an effective technique to enhance students' reading comprehension in the grade seven of MTsN Koto Baru Junior High School, West Sumatera, Indonesia". Therefore, in order to measure the explained hypothesis, the Ttest or paired sample test was utilised. The calculations were presented as follow (Notoatmodjo, 2010):

Table 5: Paired sample test of the research

Paired Samples Test

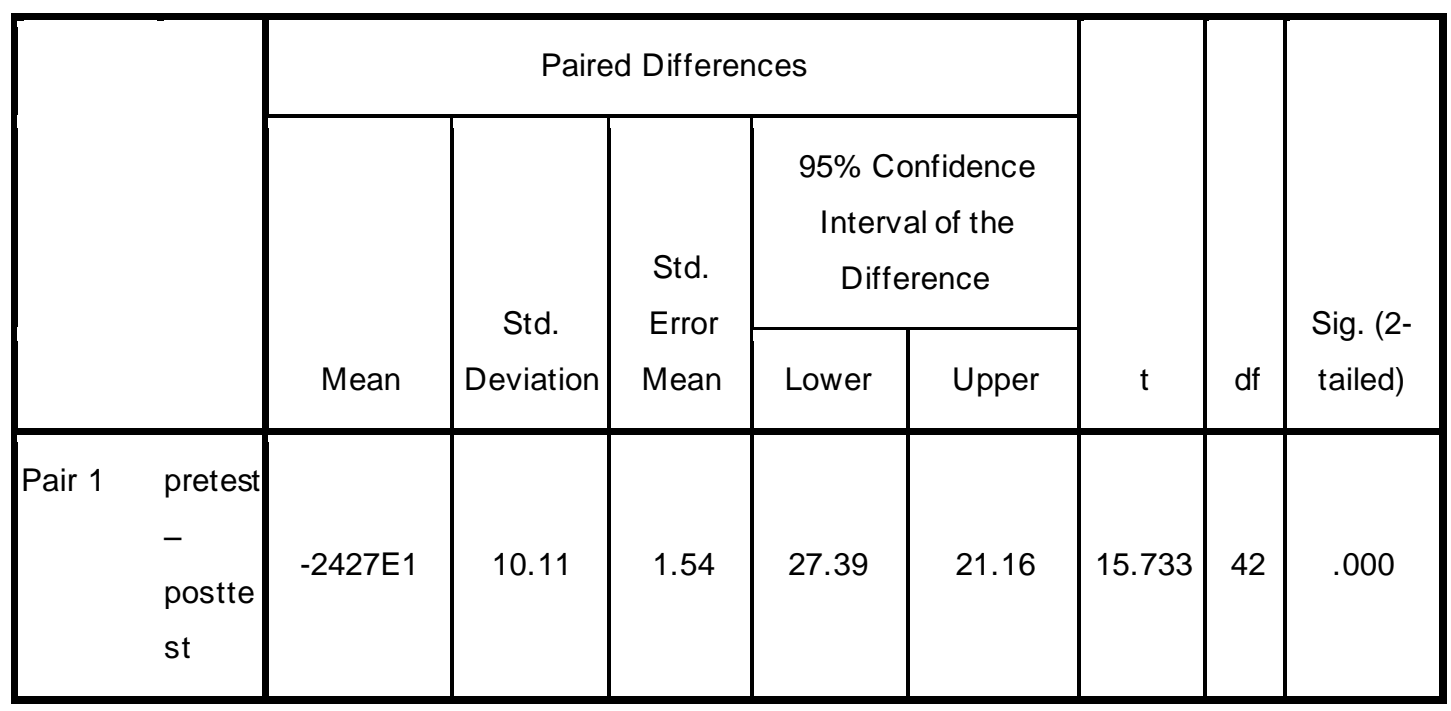

The obtained data were analysed by using the statistical software of computer program namely the SPSS 16, and it was found from the T-test that sig (2. tailed) was 0.00. If sig (2. tailed) was lower than $0.05, \mathrm{H}_{0}$ was rejected. Thus, it can be concluded that the hypothesis of the effectiveness of the CIRC technique in enhancing students' reading comprehension was statistically accepted (Notoatmodjo, 2010).

\section{Discussions}

The main aim of this research was to measure the effectiveness of the CIRC on student's reading comprehension in the MTsN Koto Baru Junior High School. This study proved that there was a significant difference between the students' reading comprehension before the given treatment (pre-test) and after the treatment (post-test). The result indicated that the CIRC was effective to increase students' reading comprehension. It is relevant with the notion of the CIRC proposed by Slavin (2005), stating that CIRC has many advantages in enhancing students' reading comprehension skills because it assigns students working in reading group activities, leading them to be more highly-motivated and critical to read the given texts.

Moreover, the result is also consistent with another study conducted by Choirunisa (2014), showing that the practice of CIRC was effective to enhance students' reading comprehension. Additionally, Sundary (2013) also conducted a study within the same topic, in which it was found that teaching reading by using CIRC offered a 
significant impact on student's reading comprehension. It could be proven from sig (2. tailed), which was 0.00 . This Sundary's findings were also found in this current research, in which the sig (2. tailed) was 0.00 . Therefore, if the sig (2. tailed) was lower than 0.05 , it means the given treatment namely the CIRC was effective to increase students' reading comprehension (Notoatmodjo, 2010).

\section{Conclusions and Suggestions}

\section{Conclusions}

The conclusion of this research was drawn in accordance with the result of the data analysis in the previous part. There were significant differences between the pre-test and post-test scores; the average score for the pre-test was 58.9, whereas 83.2 was counted for the post-test. It means that there was an improvement of the students' achievement regarding their reading comprehension abilities before the treatment (pre-test) and after CIRC was applied as the treatment (post-test). Moreover, the result between the pre-test and post-test was calculated by using the SPSS 16, showing that the sig (2. tailed) was 0.00 . Hence, if the sig (2. tailed) was lower than 0.05 , it can be concluded that the use of CIRC was effective to increase students' reading comprehension in the MTsN Koto Baru Junior High School (Notoatmodjo, 2010).

\section{Suggestions}

Based on the research findings, the researcher suggests for English teachers to consider using the CIRC in teaching reading comprehension besides other techniques since it may become an effective technique to improve students' reading comprehension if it is applied wisely. For other researchers, since this technique is not perfect yet, the researcher hopes that the next researchers might improve or make this research as a reference to expand and conduct other studies. It is hoped as well that this research might be considered by Indonesian educational stakeholders as valuable insights into creating a specific training programme to EFL teachers regarding reading strategies that can be used by them to tackle reading comprehension issues in the Indonesian junior high school context.

\section{Acknowledgement}

This paper is fully funded by the Indonesia Endowment Fund for Education (Lembaga Pengelola Dana Pendidikan/LPDP), Ministry of Finance, Republic of Indonesia as the part of Scholarship Contract No. PRJ800/LPDP.3/2017 concerning International Conference.

\section{References}

Ali, M. (2014). Riset pendidikan. Jakarta: PT Bumi Aksara.

Brown, H. D. (2004). Language assesment: Principle and classroom practices. New York: Pearson Education.

Choirunisa. (2014). Improving the reading comprehension ability of grade VIII students of SMP Islam Terpadu Abu Bakar Yogyakarta through the use of cooperative integrated reading and composition in the academic year of 2013/2014 (Thesis). Retrieved from https://eprints.uny.ac.id/18478/1/Choirunisa\%2008202241047.pdf

Floris, F. D., \& Divina, M. (2009). A study on the reading skills of EFL university students. TEFLIN Journal, 20(1), 37-47. doi: 10.15639/teflinjournal.v20i1/37-47

Guthrie, J. T., \& Davis, M. H. (2003). Motivating struggling readers in middle school through an engagement model of classroom practice. Reading \& Writing Quarterly, 19(1), 59-85. doi: 10.1080/10573560308203

Hite, S. (2009). Improving problem solving by improving reading skills (Master thesis). Retrieved from http://digitalcommons.unl.edu/mathmidsummative/9/

Klingner, J. K. (2007). Teaching reading comprehension to students with learning difficulties. New York: Guilford. 
Liu, S., \& Wang, J. (2015). Reading cooperatively or independently? Study on ELL student reading development. Reading Matrix: An International Online Journal, 15(1), 102-120. Retrieved from http://www.readingmatrix.com/archive

Mehl, M. C. (1985). The cognitive difficulties of first year physics students at the University of the Western Cape and various compensatory programmers (Doctoral dissertation). Retrieved from http://hdl.handle.net/11427/15889

Ministry of Education and Culture (2013). The regulation of the Minister of Education and Culture of Republic Indonesia 2013 concerning the basic competence of junior high school. Jakarta: Author.

Neuman, S. B., Kaefar, T., \& Pinkam, A. (2014). Building background knowledge. The Reading Teacher, 68(2), 145-148. doi: $10.1002 / \operatorname{trtr} .1314$

Notoatmodjo, S. (2010). Metodologi penelitian kesehatan. Jakarta: Rineka Cipta.

Ozdemir, A. S. (2009). The effect of reading comprehension abilities primary school students over their problem-solving achievement. Reading Improvement, 46(2), 88-98. Retrieved from http://www.freepatentsonline.com/article/Reading-Improvement/201548610.html

Slavin, R. E. (1996). Cooperative learning in middle and secondary schools. The Clearing House, 69(4), 200204. Retrieved from http://www.tandfonline.com/toc/vtch20/current

Slavin, R. E. (2005). Cooperative learning: Theory research and practice. Bandung: Nusa Media.

Snow, C. E. (2002). Reading for understanding toward an R and D program in reading comprehension. US: Rand Publication.

Sundary, D. (2013). The effect of cooperative integrated reading and composition (CIRC) on students' reading comprehension (Thesis). Retrieved from http://id.portalgaruda.org

Syatriana, E. (2013). Developing the students' reading comprehension through cognitive reading strategies of the first-year students of SMAN 16 Makassar (Thesis). Retrieved from http://engl.niu.edu/international/_images/Eny\%20Syatriana.pdf

Varisoglu, B. (2016). Influence of cooperative integrated reading and composition technique on foreign students' reading and writing skills in Turkish. Educational Research and Reviews, 11(12), 1168-1179. doi: 10.5897/ERR2016.2744 


\section{Appendices}

\section{Appendix I: Pre-test score}

\begin{tabular}{|c|c|c|}
\hline No & STUDENT & $\begin{array}{c}\text { Score } \\
\text { Pre- } \\
\text { Test }\end{array}$ \\
\hline 1 & $\mathrm{AR}$ & 56 \\
\hline 2 & AS & 48 \\
\hline 3 & AEA & 60 \\
\hline 4 & AS & 44 \\
\hline 5 & AAA & 52 \\
\hline 6 & BS & 52 \\
\hline 7 & DAP & 80 \\
\hline 8 & $\mathrm{DL}$ & 68 \\
\hline 9 & DPS & 64 \\
\hline 10 & ER & 64 \\
\hline 11 & $\mathrm{EV}$ & 72 \\
\hline 12 & FCK & 64 \\
\hline 13 & HVR & 68 \\
\hline 14 & IW & 64 \\
\hline 15 & MAR & 52 \\
\hline 16 & MSS & 44 \\
\hline 17 & MDT & 56 \\
\hline 18 & MLH & 72 \\
\hline 19 & NA & 76 \\
\hline 20 & NFS & 48 \\
\hline 21 & ONN & 68 \\
\hline 22 & $\mathrm{OY}$ & 44 \\
\hline 23 & RZS & 56 \\
\hline 24 & RR & 64 \\
\hline 25 & RHS & 76 \\
\hline 26 & RT & 52 \\
\hline 27 & RA & 52 \\
\hline 28 & $\mathrm{RS}$ & 52 \\
\hline 29 & RAT & 56 \\
\hline 30 & SR & 52 \\
\hline 31 & SMU & 64 \\
\hline 32 & SA & 52 \\
\hline 33 & SW & 52 \\
\hline 34 & $\mathrm{SL}$ & 72 \\
\hline
\end{tabular}


Dodi Widia Nanda / The Effectiveness of Cooperative Integrated Reading and Composition ....

\begin{tabular}{|c|c|c|}
35 & SA & 68 \\
\hline 36 & SY & 52 \\
\hline 37 & SAK & 68 \\
\hline 38 & TK & 48 \\
\hline 39 & VAN & 60 \\
\hline 40 & WA & 56 \\
\hline 41 & WNH & 64 \\
\hline 42 & YT & 48 \\
\hline 43 & ARE & 52 \\
\hline & AVERAGE & $\mathbf{5 8 . 9}$ \\
\hline
\end{tabular}

Appendix II: Post-test score

\begin{tabular}{|c|c|c|}
\hline No & STUDENT & $\begin{array}{c}\text { Score } \\
\text { Pre- } \\
\text { Test }\end{array}$ \\
\hline 1 & AR & 76 \\
\hline 2 & AS & 80 \\
\hline 3 & AEA & 84 \\
\hline 4 & AS & 68 \\
\hline 5 & AAA & 80 \\
\hline 6 & BS & 88 \\
\hline 7 & DAP & 88 \\
\hline 8 & $\overline{D L}$ & 92 \\
\hline 9 & DPS & 92 \\
\hline 10 & ER & 92 \\
\hline 11 & $\mathrm{EV}$ & 72 \\
\hline 12 & FCK & 96 \\
\hline 13 & HVR & 80 \\
\hline 14 & IW & 88 \\
\hline 15 & MAR & 88 \\
\hline 16 & MSS & 76 \\
\hline 17 & MDT & 80 \\
\hline 18 & MLH & 76 \\
\hline 19 & NA & 96 \\
\hline 20 & NFS & 60 \\
\hline 21 & ONN & 92 \\
\hline 22 & $\overline{O Y}$ & 72 \\
\hline 23 & RZS & 60 \\
\hline 24 & $\mathrm{RR}$ & 80 \\
\hline 25 & RHS & 92 \\
\hline
\end{tabular}


Proceeding of the $5^{\text {th }}$ International Conference on Education, Vol. 5, 2019, pp. 8-20

\begin{tabular}{|c|c|c|}
\hline 26 & RT & 84 \\
\hline 27 & RA & 80 \\
\hline 28 & RS & 88 \\
\hline 29 & RAT & 68 \\
\hline 30 & SR & 76 \\
\hline 31 & SMU & 92 \\
\hline 32 & $\overline{S A}$ & 88 \\
\hline 33 & SW & 76 \\
\hline 34 & SL & 88 \\
\hline 35 & $\overline{\mathrm{SA}}$ & 96 \\
\hline 36 & SY & 84 \\
\hline 37 & SAK & 88 \\
\hline 38 & TK & 96 \\
\hline 39 & VAN & 92 \\
\hline 40 & WA & 76 \\
\hline 41 & WNH & 84 \\
\hline 42 & YT & 80 \\
\hline 43 & ARE & 92 \\
\hline \multicolumn{2}{|c|}{ AVERAGE } & 83.2 \\
\hline
\end{tabular}

